\title{
Perencanaan Pondasi Tiang Pancang Dengan Memperhitungkan Pengaruh Likuifaksi Pada Proyek Pembangunan Hotel Di Lombok
}

\author{
M. Ilham Gumilang S., Prof. Ir. Indrasurya B. Mochtar, M.Sc., Ph.D., Dr. Yudhi Lastiasih, S.T., M.T. \\ Jurusan Teknik Sipil, Fakultas Teknik Sipil dan Perencanaan, Institut Teknologi Sepuluh Nopember (ITS) \\ Jl. Arief Rahman Hakim, Surabaya 60111 Indonesia \\ e-mail : indramochtar.mochtar@gmail.com; yudhi.lastiasih@gmail.com
}

\begin{abstract}
Abstrak -- Salah satu bahaya yang dihadapi dalam merencanakan bangunan pada kondisi tanah pasir adalah likuifaksi. Likuifaksi adalah suatu kondisi berubahnya perilaku tanah dari padat menjadi cair akibat adanya getaran atau beban sklik. Salah satu penyebab dapat terjadinya likuifaksi adalah gempa. Maka dari itu, jika mendesain bangunan yang berada pada kondisi tanah pasir serta daerah gempa tinggi, harus dilakukan analisa zona likuifaksi. Saat ini terdapat sebuah proyek pembangunan hotel di Pantai Malimbu, Lombok. Proyek tersebut berada di tanah dominan pasir dan juga termasuk daerah dengan resiko gempa tinggi. Pada perencanaan yang telah dilakukan, pihak perencana tidak melakukan analisa terhadap zona likuifaksi dan pengurangan daya dukung pondasi tiang pancang akibat dari likuifaksi. Untuk menangggulangi adanya bahaya likuifaksi, hanya dilakukan dengan menggunakan angka keamanan (safety factor $)=5$. Pada tugas akhir ini akan dilakukan perencanaan pondasi tiang pancang dengan membandingkan kondisi likuifaksi dan kondisi tidak likuifaksi yang ditinjau terhadap 4 kondisi. Kondisi 1 adalah kondisi tidak likuifaksi, ada beban gempa, dan safety factor $=5$. Kondisi 2 adalah kondisi likufaksi, safety factor $=1.5$. Kondisi 3 adalah kondisi tidak likuifaksi, ada beban gempa, safety factor $=2$. Kondisi 4 adalah kondisi tidak likuifaksi, tidak ada beban gempa, safety factor $=3$. Struktur bangunan atas akan di modelkan dengan program bantu SAP 2000. Tujuannya untuk mengetahui reaksi pada dasar bangunan. Dari hasil perhitungan yang telah dilakukan maka didapatkan jumlah kebutuhan pondasi tiang pancang untuk masing-masing kondisi.Kondisi 1 menggunakan PC spun pile diameter $1000 \mathrm{~mm}$ sejumlah 192 buah. Kondisi 2 menggunakan bored pile diameter $800 \mathrm{~mm}$ sejumlah 192 buah. Kondisi 3 dan kondisi 4 menggunakan PC spun pile diameter $600 \mathrm{~mm}$ sejumlah 192 buah dan 256 buah untuk masing-masingnya.
\end{abstract}

Kata kunci : Gempa, Likuifaksi , SAP 2000, Tanah Pasir, Tiang Pancang.

\section{PENDAHULUAN}

\section{A. Latar Belakang}

Indonesia merupakan daerah rawan gempa. Hal ini dapat dilihat secara geografis bahwa Indonesia merupakan daerah pertemuan 4 buah lempeng dunia yaitu, lempeng IndoAustralia, lempeng Eurasia, lempeng Filipina, dan lempeng Pasific. Keberadaan batas lempeng biasanya mencerminkan adanya aktifitas geologis di daerah tersebut seperti, gempa bumi, pembentukan gunung berapi, atau palung laut.

Saat ini sedang berlangsung sebuah proyek pembangunan hotel di Lombok. Proyek tersebut berlokasi di daerah dekat pantai. Kondisi tanah di lokasi proyek adalah dominan pasir dengan konsistensi tanah very loose hingga medium dense. Tanah pasir yang jenuh air dengan konsistensi very loose loose $(\mathrm{NSPT}<10)$ berpotensi terhadap terjadinya likuifaksi (Seed \& Idriss, 1982). Likuifaksi adalah kondisi berubahnya perilaku tanah dari padat menjadi cair akibat adanya getaran atau beban siklik, salah satunya yaitu gempa atau kondisi tanah pada saat tegangan total sama dengan tegangan air sehingga tegangan efektif tanah menjadi sama dengan nol $\left(\sigma^{\prime}=\sigma-\mathrm{u}=0\right)$. Pada saat terjadi gempa, lapisan tanah yang berpotensi terhadap likuifaksi akan kehilangan kemampuan daya dukungnya, sehingga berpengaruh terhadap daya dukung pondasi. Berdasarkan SNI 1726:2012, pulau Lombok memiliki nilai $\mathrm{S}_{\mathrm{s}}=0.9-1.0 \mathrm{~g}$ dan $\mathrm{S}_{1}=0.4-0.5 \mathrm{~g}$. Oleh karena itu, dapat dikatakan bahwa Lombok merupakan daerah dengan resiko gempa kuat.

Proyek tersebut direncanakan menggunakan struktur pondasi tiang pancang. Pada perencanaan struktur pondasi, pihak perencana hanya menggunakan SF (safety factor) $=5$ guna menanggulangi bahaya potensi likuifaksi yang ada. Tidak terdapat perhitungan terhadap pengurangan daya dukung pondasi tiang pancang akibat dari likuifaksi itu sendiri.

Berdasarkan kondisi yang telah dijelaskan sebelumnya, maka pada Tugas Akhir ini akan membahas bagaimana perencanaan pondasi tiang pancang pada proyek pembangunan hotel di Lombok dengan memperhitungkan pengaruh likuifaksi tanah.

\section{B. Rumusan Masalah}

Berdasarkan latar belakang yang telah diuraikan di atas, maka permasalahan yang akan di bahas pada tugas akhir ini adalah :

1) Berapa total tebal lapisan tanah yang berpotensi mengalami likuifaksi?

2) Berapa daya dukung tanah di lokasi proyek jika tanpa pengaruh likuifaksi?

3) Berapa daya dukung tanah di lokasi proyek jika terpengaruh likuifaksi?

4) Berapa besar perbedaan daya dukung pondasi tiang pancang apabila tanpa pengaruh likuifaksi dan apabila memperhitungkan pengaruh likuifaksi?

5) Bagaimana perbedaan kebutuhan dimensi dan jumlah pondasi tiang pancang, apabila tanpa pengaruh likuifaksi dan apabila memperhitungkan pengaruh likuifaksi?

6) Bagaimana konfigurasi pile cap struktur pondasi?

7) Bagaimana perbedaan biaya terhadap kebutuhan pondasi tiang pancang apabila perencanaan tanpa pengaruh likuifaksi dan apabila memperhitungankan pengaruh likufaksi? 


\section{Tujuan}

Tujuan yang ingin dicapai dalam pengerjaan Tugas Akhir ini antara lain:

1) Mengetahui total tebal lapisan tanah yang berpontesi mengalami likuifaksi.

2) Mengetahui daya dukung tanah dalam kondisi non likuifaksi.

3) Mengetahui daya dukung tanah dalam kondisi likuifaksi.

4) Mengetahui perbedaan daya dukung pondasi tiang apabila tanpa pengaruh likuifaksi dan apabila memperhitungkan pengaruh likuifaksi.

5) Mengetahui perbedaan kebutuhan dimensi dan jumlah pondasi tiang pancang apabila tanpa pengaruh likuifaksi dan apabila memperhitungkan pengaruh likuifaksi.

6) Mengetahui konfigurasi dari pile cap struktur pondasi.

7) Mengetahui seberapa besar perbedaan biaya terhadap kebutuhan tiang pancang apabila tanpa pengaruh likuifaksi dan perencanaan dengan memperhitungkan pengaruh likuifaksi.

\section{Manfaat}

Manfaat yang bisa didapat dari penyusunan Tugas Akhir ini adalah sebagai berikut :

1) Menambah wawasan dan mengaplikasikan teori yang didapat selama masa perkuliahan.

2) Sebagai referensi pada perencanaan pondasi di daerah yang berpotensi likuifaksi.

3) Sebagai alternatif pada perencanaan hotel di Lombok.

\section{METODOLOGI}

Metode yang digunakan dalam perencanaan adalah sebagai berikut:

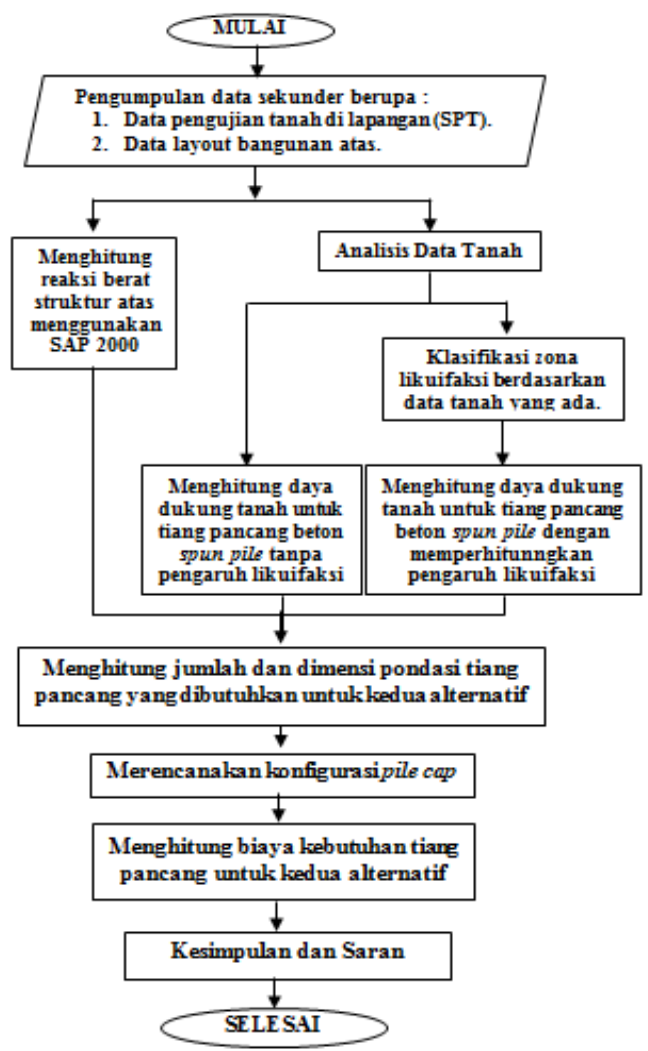

Gambar 1. Diagram Alir Metodologi Perencanaan

\section{ANALISA DATA TANAH DAN PERMODELAN STRUKTUR}

\section{A. Data Tanah}

Data tanah yang digunakan dalam pengerjaan tugas akhir ini adalah berupa data bore log. Hal tersebut dikarenakan pada pengerjaan proyek hanya dilakukan uji bore log dan tidak dilakukan uji laboratorium guna mendapatkan parameter fisis tanah lainnya. Maka dari itu perlu dilakukan korelasi NSPT guna mendapatkan parameter fisis tanah lainnya.

\section{B. Korelasi Data $N_{s p t}$}

Sebagai tahap awal dalam menentukan parameter fisis tanah lainnya, nilai $\mathrm{N}_{\mathrm{SPT}}$ dari data bore $\log$ harus dikoreksi terlebih dahulu terhadap muka air tanah dan juga tegangan overburden [1]. Koreksi terhadap muka air tanah $\left(\mathrm{N}_{1}\right)$ dan koreksi terhadap tegangan overburden $\left(\mathrm{N}_{2}\right)$ dapat ditentukan dengan rumus berikut :

$$
\begin{aligned}
& \mathrm{N}_{1}=15+\frac{(N-15)}{2} \\
& \mathrm{~N}_{1}=0.6 \mathrm{~N} \\
& \mathrm{~N}_{2}=\frac{4 \mathrm{~N}_{1}}{1+0.4 \sigma 0}
\end{aligned}
$$

Parameter fisis tanah yang dibutuhkan untuk perencanaan selanjutnya adalah berat jenis tanah $(\gamma)$, sudut geser tanah (Ø) dan kerapatan relatif (relative density, Dr). Dalam melakukan korelasi kali ini, penulis menggunakan tabel korelasi J.E. Bowles [2].

\section{Analisa Zona Likuifaksi}

Untuk mengetahui lapisan tanah yang berpotensi mengalami likuifaksi, maka perlu dilakukan analisa zona likuifaksi pada lapisan tanah yang jenuh air [6]. Pada penulisan tugas akhir ini analisa zona likuifaksi dilakukan berdasarkan aspek tegangan dari data $\mathrm{N}_{\mathrm{SPT}}$, yaitu setiap kedalaman 0.5 meter. Analisa likuifaksi dapat dianalisa dengan perumusan sebagai berikut :

$$
\begin{aligned}
& C S R=0,65 \times\left(\frac{a_{\text {max }}}{g}\right) \times\left(\frac{\sigma_{v o}}{\sigma_{v o}^{\prime}}\right) \times r_{d} \\
& C R R_{7,5}=\exp \left(\frac{\left(N_{1}\right)_{60 c s}}{14,1}+\left(\frac{\left(N_{1}\right)_{60 c s}}{126}\right)^{2}+\left(\frac{\left(N_{1}\right)_{60 c s}}{23,6}\right)^{3}+\left(\frac{\left(N_{1}\right)_{60 c s}}{25,4}\right)^{4}-2,8\right) \\
& C R R_{M, \sigma_{v}^{\prime}}=C R R_{M=7.5, \sigma_{v}^{\prime}=1} \cdot M S F \cdot K_{\sigma}
\end{aligned}
$$

Lapisan tanah berpotensi likuifaksi apabila memiliki nilai $\mathrm{SF}<1$. Dimana $\mathrm{SF}=\mathrm{CRR}_{\mathrm{M}} / \mathrm{CSR}$. Zona lapisan tanah yang berpotensi likuifaksi dapat dilihat pada Gambar 2, dimana zona likuifaksi adalah ketika $\mathrm{CRR}_{\mathrm{M}}<\mathrm{CSR}$.

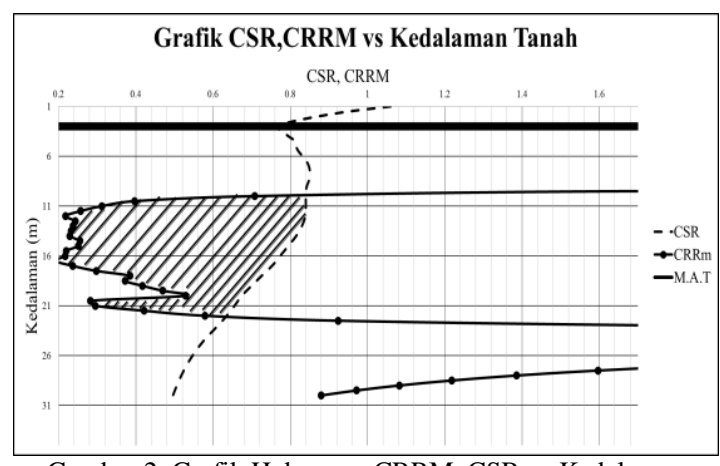

Gambar 2. Grafik Hubungan CRRM, CSR vs Kedalaman 
Berdasarkan Gambar 2 di atas maka dapat diketahui bahwa total tebal lapisan yang mengalami likuifaksi adalah 12.5 meter.

\section{Permodelan Struktur Bangunan Atas}

Permodelan struktur bangunan atas dilakukan dengan program bantu analisa struktur SAP 2000. Permodelan ini bertujuan untuk mendapatkan reaksi perletakan di dasar gedung yang nantinya akan digunakan pada perhitungan perencanaan pondasi. Struktur yang dimodelkan adalah bangunan hotel yang terdiri dari 13 lantai. Permodelan dilakukan untuk dua kondisi. Kondisi pertama adalah permodelan saat kondisi tidak likuifaksi dan kondisi kedua adalah permodelan saat kondisi likuifaksi.

\section{PERENCANAAN PONDASI}

\section{A. Daya Dukung Tanah Untuk Tiang Pancang}

Perhitungan daya dukung tanah untuk tiang pancang dilakukan berdasarkan data $\mathrm{N}_{\mathrm{SPT}}$ yang telah dikoreksi terhadap muka air tanah dan tegangan overburden. Setelah dilakukan koreksi maka selanjutnya dapat dihitung daya dukung tanah untuk tiang pancang (Qultimate) dengan diameter tiang rencana $600 \mathrm{~mm}, 800 \mathrm{~mm}$, dan $1000 \mathrm{~mm}$. Perhitungan dilakukan dengan menggunakan persamaan Meyerhof [1], sebagai berikut :

$$
Q_{\text {ULTIMATE }}=\left(C n \times A_{\text {ujung }}\right)+\left(\sum C l i \times A s i\right)
$$

Pada saat kondisi likuifaksi, maka daya lekat tanah (friction) pada kedalaman tanah yang mengalami likuifaksi menjadi hilang atau sama dengan nol. Daya dukung tanah pada saat kondisi likuifaksi dan tidak likuifaksi dapat dilihat pada Gambar 3.

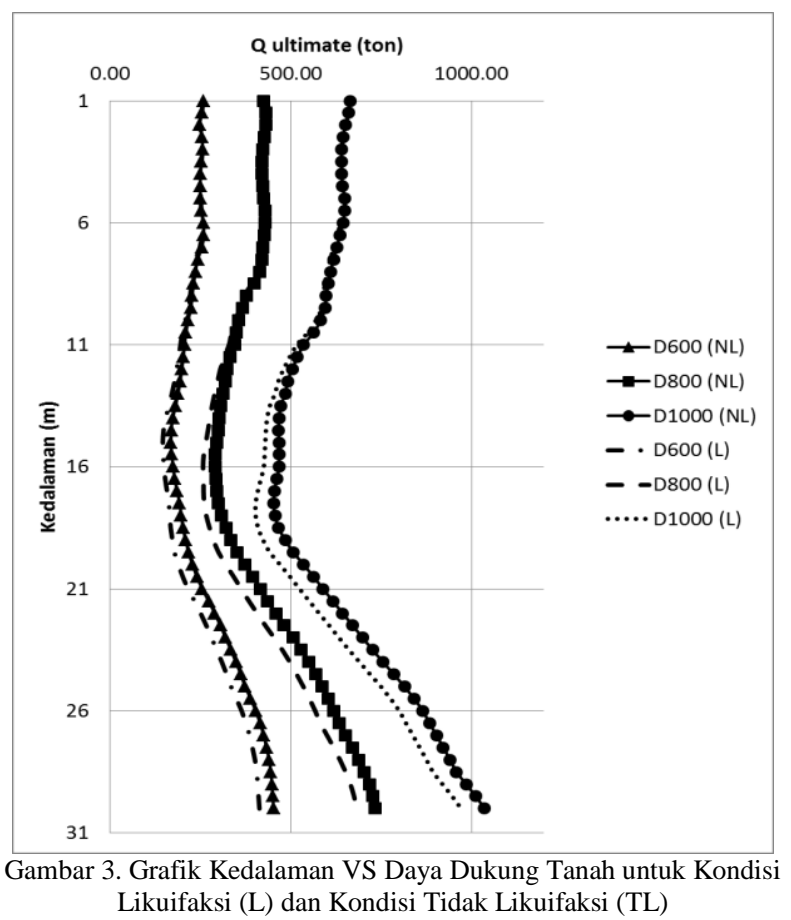

\section{B. Kebutuhan Pondasi Tiang Pancang}

Jenis pondasi tiang pancang yang digunakan dalam penulisan tugas akhir ini adalah tiang pancang beton precast spun pile. Perencanaan kebutuhan jumlah pondasi tiang pancang dibagi menjadi beberapa kondisi sebagai berikut :
1)Kondisi 1 adalah kondisi tidak likuifaksi, tetap meninjau beban gempa, dan $\mathrm{SF}=5$.

2)Kondisi 2 adalah kondisi likuifaksi, meninjau beban gempa, dan $\mathrm{SF}=1.5$.

3)Kondisi 3 adalah kondisi tidak likuifaksi, namun tetap meninjau beban gempa, dan $\mathrm{SF}=2$.

4)Kondisi 4 adalah kondisi tidak likuifaksi, tidak meninjau beban gempa, dan $\mathrm{SF}=3$.

Berikut adalah tahapan-tahapan dalam merencanakan jumlah kebutuhan pondasi tiang pancang.

\section{Jenis Tiang Pancang}

Pada tahap awal, pondasi direncanakan menggunakan tiang pancang beton precast spun pile diameter $600 \mathrm{~mm}, 800 \mathrm{~mm}$ dan $1000 \mathrm{~mm}$. Namun apabila dalam perhitungan lebih lanjut jenis tiang pancang yang direncanakan tidak memenuhi syarat, maka akan diganti dengan jenis pondasi yang memungkinkan untuk dipakai.

\section{Kedalaman Tiang}

Untuk menentukan kedalaman tiang pancang, dipakai nilai Qijin tanah dimana setara dengan 1/2 Qallowable axial bahan tiang pancang. Qallowable bahan tiang diketahui 229.5 ton, dan nilai 1/2 Qallowable bahan adalah 114.75 ton. Sehingga dipakai kedalaman tiang pada 26 meter dengan Qijin tanah sebesar 130.01 ton.

\section{Gaya Reaksi di Perletakan Bangunan}

Gaya reaksi perletakan didapatkan berdasarkan joints reaction pada program bantu analisa SAP 2000. Nilai yang dipakai adalah Fz, Mx, dan My.

\section{Konfigurasi Tiang Pancang}

Konfigurasi tiang pancang direncanakan dengan jarak antar tiang $(\mathrm{S})=2.5 \mathrm{D}$, sedangkan jarak tiang ke tepi pile cap terluar $=\mathrm{D}$, dengan $\mathrm{D}$ adalah diameter tiang.

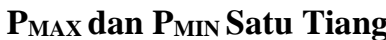

Gaya yang terjadi pada 1 tiang akibat beban reaksi perletakan, dapat dihitung dengan persamaan berikut :

$P \max =\frac{\sum \mathrm{Fz}}{n}+\frac{M y \cdot X \max }{\sum X i^{2}}+\frac{M x \cdot Y \max }{\sum Y i^{2}}$

\section{Efisiensi Tiang Pancang Grup}

Efisiensi tiang pancang grup didapatkan berdasarkan perumusan Sieler Keeney sebagai berikut :

$E f=\left[1-\frac{365}{\left(75 s^{2}-7\right)} x\left(\frac{m+n-2}{m+n-1}\right)\right]+\frac{0,3}{m+n}$

\section{Pijin Tekan dan Pijin Tarik}

Setelah didapatkan daya dukung tanah ultimate pada perhitungan sebelumnya, maka selanjutnya perlu ditentukan Pijin satu tiang yang berguna sebagai batasan dari Pmax dan Pmin satu tiang yang terjadi. Pijin satu tiang dapat dihitung sebagai berikut :

1) $P_{\mathrm{ijin}}=Q_{\text {ultimate }} / \mathrm{SF}$

2) $P_{i j i n}$ grup $=P_{i j i n}$ tekan $x$ Effisiensi

3) $P_{i j i n}$ berlebih $=P_{i j i n}$ grup $x$ Persentase lebih

\section{Kontrol PMAX dan P $P_{\text {MIN }}$ Satu Tiang}

Gaya aksial maksimum dan minimum yang terjadi pada satu tiang harus dikontrol agar tidak melebihi batas ijinnya. $\mathrm{P}_{\mathrm{MAX}}$ satu tiang dikontrol terhadap $\mathrm{P}_{\text {IJIN TEKAN BERLEBIH }}$ dan $\mathrm{P}_{\text {MIN }}$ satu tiang dikontrol terhadap $\mathrm{P}_{\text {IJIN }}$ TARIK BERLEBIH. Hasil 
kontrol tersebut nantinya akan menentukan jumlah kebutuhan pondasi tiang pancang. Jumlah kebutuhan pondasi dapat dilihat pada Tabel 1 .

Tabel 1

Jumlah Kebutuhan Pondasi

\begin{tabular}{ccc}
\hline \hline $\begin{array}{c}\text { Kondisi } \\
\text { Perencanaan }\end{array}$ & $\begin{array}{c}\text { Jumlah } \\
\text { Tiang }\end{array}$ & $\begin{array}{c}\text { Dimensi } \\
\text { Tiang }\end{array}$ \\
\hline KONDISI 1 & 192 & $1000 \mathrm{~mm}$ \\
KONDISI 2 & 192 & $800 \mathrm{~mm}$ \\
KONDISI 3 & 192 & $600 \mathrm{~mm}$ \\
KONDISI 4 & 256 & $600 \mathrm{~mm}$ \\
\hline \hline
\end{tabular}

\section{Konfigurasi Pondasi Tiang Pancang}

Berdasarkan perhitungan kebutuhan pondasi tiap joint yang direncanakan, maka didapatkan beberapa jenis pilecap. Tipe pilecap yang ada berdasarkan kebutuhan jumlah tiang pancang yang direncanakan dapat dilihat pada Tabel 2. Tabel 2 Tipe Pile Cap

\begin{tabular}{|c|c|c|c|c|c|c|}
\hline Tipe & Diameter & \multirow{2}{*}{$\begin{array}{c}\text { Jumlah } \\
\text { Pile cap }\end{array}$} & \multicolumn{2}{|c|}{ Konfigurasi } & \multicolumn{2}{|c|}{ Dimensi } \\
\cline { 4 - 7 } & Tiang (mm) & Tiang & $\mathrm{n}$ (kolom) & $\mathrm{m}$ (baris) & $\mathrm{x}$ (meter) & $\mathrm{y}$ (meter) \\
\hline Tipe 1 & 600 & 4 & 2 & 2 & 2.7 & 2.7 \\
\hline Tipe 2 & 600 & 6 & 2 & 3 & 2.7 & 4.2 \\
\hline Tipe 3 & 800 & 4 & 2 & 2 & 3.6 & 3.6 \\
\hline Tipe 4 & 800 & 8 & 4 & 2 & 7.6 & 3.6 \\
\hline Tipe 5 & 1000 & 4 & 2 & 2 & 4.5 & 4.5 \\
\hline Tipe 6 & 1000 & 8 & 4 & 2 & 9.5 & 4.5 \\
\hline
\end{tabular}

\section{Kontrol Ketahanan Tiang Terhadap Gaya Horizontal}

Setelah direncanakan untuk dapat menahan gaya-gaya reaksi diperletakan, pondasi tiang pancang juga perlu dikontrol terhadap gaya horizontal. Defleksi dan momen yang terjadi pada tiang pancang tidak boleh melebihi batasan yang telah ditentukan. Berikut adalah perumusan untuk menentukan defleksi dan momen yang terjadi pada tiang :

1) Menentukan nilai $T$

$$
T=\left(\frac{E x I}{f}\right)^{\frac{1}{5}}
$$

2) Menentukan nilai defleksi $(\delta P)$ pada tiang

$$
\delta p=F_{g}\left(\frac{P T^{\mathrm{a}}}{E I}\right)<2.54 \mathrm{~cm}
$$

3) Menentukan nilai momen (Mp) pada tiang

$$
M p=F m . P . T<\mathrm{M}_{\mathrm{CRACK}}
$$

Hasil kontrol ketahanan tiang pancang terhadap gaya horizontal untuk semua jenis pile cap yang direncanakan dapat dilihat pada Tabel 3 .

Tabel 3

Kontrol Tiang Pancang Terhadap Gaya Lateral

\begin{tabular}{|c|c|c|c|c|c|}
\hline Tipe & Diameter & \multicolumn{2}{|c|}{ Kontrol Defleksi } & \multicolumn{2}{|c|}{ Kontrol Momen } \\
\cline { 3 - 6 } Pilecap & Tiang $(\mathrm{mm})$ & Defleksi $(\mathrm{cm})$ & Keterangan & Mp (ton.m) & Keterangan \\
\hline Tipe 1 & 600 & 0.65 & OK & -18.65 & OK \\
\hline Tipe 2 & 600 & 0.11 & OK & -3.32 & OK \\
\hline Tipe 3 & 800 & 0.29 & OK & -17.53 & OK \\
\hline Tipe 4 & 800 & 0.29 & OK & -17.53 & OK \\
\hline Tipe 5 & 1000 & 0.30 & OK & -27.54 & OK \\
\hline Tipe 6 & 1000 & 0.30 & OK & -27.54 & OK \\
\hline
\end{tabular}

\section{E. Kontrol Material Tiang Terhadap Likuifaksi}

Pada saat terjadi likuifaksi, maka tanah pada lapisan tersebut kehilangan tegangan antar partikelnya akibat dari meningkatnya tekanan air pori. Lapisan tanah yang mengalami likuifaksi akan bergerak secara horizontal dan akan membawa seluruh lapisan tanah yang ada di atasnya[3]. Maka dari itu perlu dilakukan kontrol terhadap momen yang terjadi pada tiang saat likuifaksi. Sketsa lapisan tanah saat likuifaksi dapat dilihat pada Gambar 4.

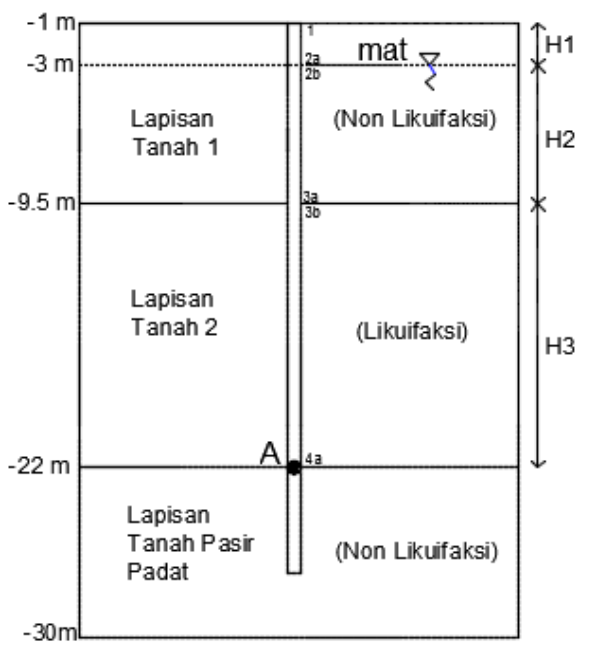

Gambar 4. Sketsa Potongan Lapisan Tanah Saat Likuifaksi

Titik A merupakan zona perbatasan antara lapisan likufaksi dan non likuifaksi. Pada titik tersebut merupakan letak momen terbesar akibat pergerakan horizontal tanah saat likuifaksi. Momen di titik A dapat diperoleh dengan cara menghitung tegangan vertikal dan tengan horizontal tanah terlebih dahulu [4]. Setelah itu sehingga diperoleh gaya yang bekerja pada tiang. Lapisan tanah likuifaksi hanya menerima $30 \%$ dari tegangan overburden total [5]. Sehingga didapat grafik tegangan horizontal tanah seperti pada Gambar 5.

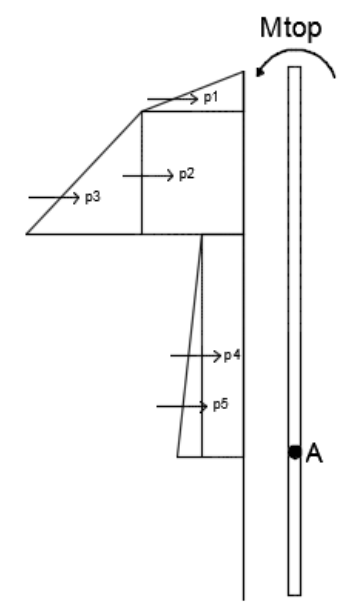

Gambar 5. Grafik Tegangan Tanah Horizontal Saat Likuifaksi [3] Berdasarkan perhitungan didapat momen sebagai berikut :

\section{$\mathrm{M}_{\mathrm{A}}=299.8$ ton.m $>\mathrm{M}_{\mathrm{Ultimate}}=117$ ton.m $(\mathrm{NOT} \mathrm{OK})$}

Nilai $\mathrm{M}_{\mathrm{A}}>\mathrm{M}_{\mathrm{ULtim}}$ tiang, maka precast spun pile D800 tidak dapat digunakan karena tidak aman terhadap likuifaksi yang terjadi. Maka selanjutnya perencanaan pondasi pada kondisi 2 menggunakan jenis bored pile. 


\section{F. Perencanaan Bored Pile}

Pondasi bored pile direncanakan berdasarkan kebutuhan dari gaya dan momen yang akan di terima pada satu tiang. Berdasarkan perhitungan yang telah dilakukan maka diperoleh data sebagai berikut :
1) Pmax satu tiang
$=258.4$ ton
2) $\mathrm{MA}_{\mathrm{A}}$
$=299.8$ ton. $\mathrm{m}$

Berdasarkan nilai Pmax dan MA maka dapat direncanakan bored pile dengan menggunakan program bantu pcaColumn. Direncanakan bored pile dengan data sebagai berikut :
1) Diameter $=800 \mathrm{~mm}$
2) Tebal selimut $\quad=40 \mathrm{~mm}$
3) Mutu beton $\quad=50 \mathrm{MPa}$
4) Dimensi tulangan $=\# 32(32 \mathrm{~mm})$
5) Jumlah tulangan $=43$ buah
6) Dimensi sengkang $=\# 10(10 \mathrm{~mm})$
7) Jenis sengkang = spiral

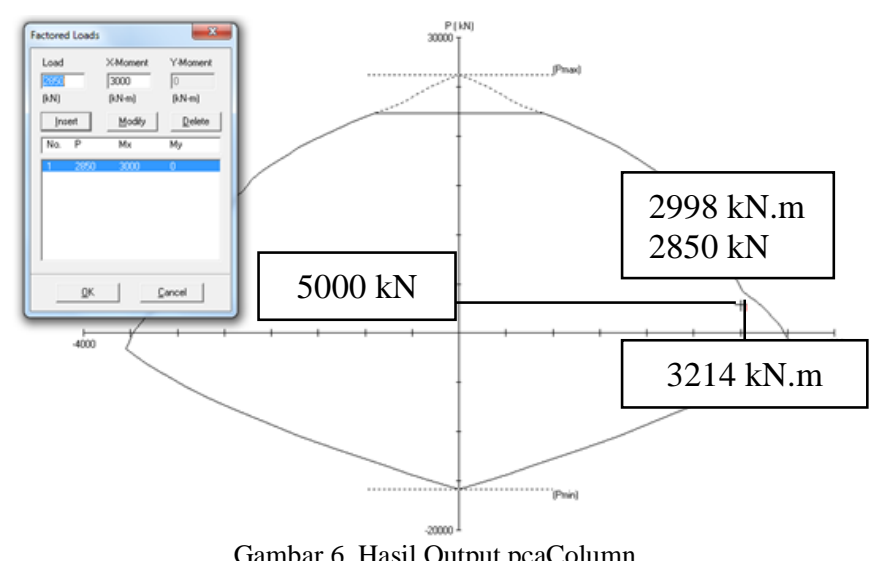

Berdasarkan Gambar 6 dapat dilihat bahwa nilai gaya dan momen yang diterima 1 tiang lebih kecil dari kapasitas tiang itu sendiri. Maka dari itu dapat disimpulkan bahwa bored pile yang direncanakan dapat menerima gaya dan momen yang ada.

\section{G. Perencanaan Pile Cap}

Pile cap harus direncanakan agar tahan terhadap gaya geser akibat kolom maupun akibat tiang dan juga dapat menahan momen lentur pada penampang kritis.

\section{Kontrol Geser Ponds}

1) Geser satu arah

$$
\begin{aligned}
& V_{c}=0.75 x \sqrt{f c^{t}} x b_{0} x d \\
& V_{U P}=\left(P_{i}\right)_{\max }-W_{f c}
\end{aligned}
$$

2) Geser dua arah

$$
\begin{aligned}
& V_{c}=0.17\left(1+\frac{2}{\beta}\right) \lambda \sqrt{f^{\prime} c} U d \\
& V_{c}=0.083\left(\frac{\alpha_{g} d}{U}+2\right) \lambda \sqrt{f^{\prime} c} U d \\
& V_{c}=0.33 \lambda \sqrt{f^{\prime} c} U d
\end{aligned}
$$

$\mathrm{P}_{\mathrm{u}}$ punch $=\mathrm{Pu}+\mathrm{Wu}-\mathrm{P}$ tiang daerah kritis

3) Geser akibat tiang

$$
\begin{aligned}
& \tau u=\frac{P u \text { tiang }}{U x d} \\
& \tau c=0.33 x \lambda_{2} x \sqrt{f^{\prime} c}
\end{aligned}
$$

\begin{tabular}{|c|c|c|c|c|c|c|c|c|c|}
\hline \multirow{3}{*}{$\begin{array}{l}\text { Tipe } \\
\text { Pilecap }\end{array}$} & \multicolumn{6}{|c|}{ Geser Ponds Akibat Kolom (ton) } & \multirow{2}{*}{\multicolumn{3}{|c|}{$\begin{array}{l}\text { Geser Ponds Akibat } \\
\text { Tiang Pancang (ton) }\end{array}$}} \\
\hline & \multicolumn{3}{|c|}{ Geser satu arah } & \multicolumn{3}{|c|}{ Geser Dua arah } & & & \\
\hline & Vu & $\emptyset \vee c$ & Kontro & Pu, punch & Vc & Kontrol & $\tau u$ & $\tau \mathrm{c}$ & Kontrol \\
\hline Tipe 1 & 174.61 & 896.51 & OK & 379.55 & 0.08 & OK & 0.813 & 2.11 & OK \\
\hline Tipe 2 & 104.66 & 1394.56 & OK & 481.92 & 826.41 & OK & $\mid 0.397$ & 2.11 & OK \\
\hline Tipe 3 & 376.18 & 1195.34 & OK & 693.02 & 826.41 & OK & 1.836 & 2.11 & OK \\
\hline Tipe 4 & 693.31 & 2523.50 & OK & 585.44 & 826.41 & OK & 0.680 & 2.11 & $\mathrm{OK}$ \\
\hline Tipe 5 & 375.41 & 1494.18 & OK & 692.40 & 826.41 & OK & 0.449 & 2.11 & OK \\
\hline Tipe 6 & 750.82 & 3154.37 & OK & 685.00 & 826.41 & OK & 0.449 & 2.11 & OK \\
\hline
\end{tabular}

Hasil kontrol geser ponds dapat dilihat pada Tabel 4.

Tabel 4

Kontrol Geser Ponds untuk Seluruh Tipe Pile Cap

\section{Perencanaan Tulangan Pile Cap}

Tulangan lentur untuk pile cap pondasi direncakan untuk dua arah. Perhitungan dilakukan untuk tulangan bagian bawah, sedangkan tulangan bagian atas direncakan $1 / 2$ dari kebutuhan tulangan bawah. Hasil perhitungan untuk kebutuhan tulangan pile cap dapat dilihat pada Tabel 5.

Tabel 5.

Penulangan Pile cap

\begin{tabular}{|c|c|c|}
\hline $\begin{array}{c}\text { Tipe } \\
\text { Pilecap }\end{array}$ & $\begin{array}{c}\text { Kebutuhan } \\
\text { Tulangan } \text { arah } \mathrm{X}\end{array}$ & $\begin{array}{c}\text { Kebutuhan } \\
\text { Tulangan } \text { arah } \mathrm{Y}\end{array}$ \\
\hline Tipe 1 & 16D25 - 150 & 16D25 - 150 \\
\hline Tipe 2 & 24D25 - 150 & 20D25 - 100 \\
\hline Tipe 3 & 28D25 - 100 & 28D25 - 100 \\
\hline Tipe 4 & 61D36 - 50 & 54D25 - 100 \\
\hline Tipe 5 & 28D25 - 150 & 28D25 - 150 \\
\hline Tipe 6 & 63D25 - 50 & 55D25 - 150 \\
\hline
\end{tabular}

\section{H. Perencanaan Biaya Kebutuhan Tiang Pancang}

Perencanaan biaya dilakukan hanya terhadap harga kebutuhan bahan dari tiang pancang dan tidak meninjau faktor-faktor pengaruh harga lainnya. Harga tiang pancang ditentukan berdasarkan informasi yang diperoleh dari sebuah kontraktor di Indonesia. Harga kebutuhan bahan tiang pancang untuk seluruh kondisi perencanaan dapat dilihat pada Tabel 6 .

Tabel 6.

Harga Kebutuhan Bahan Tiang Pancang

\begin{tabular}{|r|c|c|cr|}
\hline Kondisi & Jumlah Tiang & Dimensi & \multicolumn{2}{|c|}{ Total Harga } \\
\hline Kondisi 1 & 192 & D1000 & Rp & $6,240,000,000$ \\
\hline Kondisi 2 & 192 & D800 & Rp & $19,925,218,545$ \\
\hline Kondisi 3 & 192 & D600 & Rp & $3,744,000,000$ \\
\hline Kondisi 4 & 256 & D600 & Rp & $4,992,000,000$ \\
\hline
\end{tabular}

\section{PENUTUP}

\section{A. KESIMPULAN}

Setelah dilakukan perhitungan dan analisa sebelumnya, maka dapat diambil kesimpulan sebagai berikut :

1) Berdasarkan hasil perhitungan analisa zona likuifaksi maka dapat disimpulkan bahwa tebal total lapisan tanah yang mengalami likuifaksi adalah 12.5 meter.

2) Daya dukung tanah pada kondisi non likuifaksi adalah sebagai berikut :

a) Daya dukung tanah ultimate (Qultimate) untuk tiang pancang diameter $600 \mathrm{~mm}$ pada kedalaman 26 meter adalah 389.35 ton. 
b) Daya dukung tanah ultimate (Qultimate) untuk tiang pancang diameter $800 \mathrm{~mm}$ pada kedalaman 26 meter adalah 606.64 ton.

c) Daya dukung tanah ultimate (Qultimate) untuk tiang pancang diameter $1000 \mathrm{~mm}$ pada kedalaman 26 meter adalah 858.89 ton.

3) Daya dukung tanah pada kondisi likuifaksi adalah sebagai berikut :

a) Daya dukung tanah ultimate (Qultimate) untuk tiang pancang diameter $600 \mathrm{~mm}$ pada kedalaman 26 meter adalah 346.03 ton.

b)Daya dukung tanah ultimate (Qultimate) untuk tiang pancang diameter $800 \mathrm{~mm}$ pada kedalaman 26 meter adalah 548.88 ton.

c) Daya dukung tanah ultimate (Qultimate) untuk tiang pancang diameter $1000 \mathrm{~mm}$ pada kedalaman 26 meter adalah 786.69 ton.

4) Perbedaan daya dukung tiang pancang ditinjau untuk satu jenis pile cap yang sama. Daya dukung satu tiang untuk pile cap tipe 1 dengan D600 pada masing-masing kondisi perencanaan adalah sebagai berikut :

a) QIJIN tekan satu tiang untuk perencanaan kondisi 1 adalah 93.1 ton.

b) $Q_{\text {IJIN }}$ tekan satu tiang untuk perencanaan kondisi 2 adalah 280.236 ton.

c) $Q_{\text {IJIN }}$ tekan satu tiang untuk perencanaan kondisi 3 adalah 232.738 ton.

d) Q adalah 110.827 ton.

5) Perbedaan kebutuhan dimensi dan jumlah pondasi tiang dapat dilihat pada Tabel 7 sebagai berikut :

Tabel 7.

Kebutuhan Pondasi

\begin{tabular}{|c|c|c|c|c|}
\hline Kondisi & Jenis Tiang & Dimensi & $\begin{array}{c}\text { Jumlah } \\
\text { Tiang }\end{array}$ & $\begin{array}{c}\text { Panjang } \\
\text { Tiang }(\mathrm{m})\end{array}$ \\
\hline Kondisi 1 & Precast Spun Pile & D1000 & 192 & 26 \\
\hline Kondisi 2 & Bored Pile & D800 & 192 & 26 \\
\hline Kondisi 3 & Precast Spun Pile & D600 & 192 & 26 \\
\hline Kondisi 4 & Precast Spun Pile & D600 & 256 & 26 \\
\hline
\end{tabular}

6) Biaya bahan tiang pancang yang dibutuhkan untuk masing-masing kondisi perencanaan adalah sebagai berikut :
a) Kondisi $1=\operatorname{Rp} \quad 6.240 .000 .000$
b) Kondisi $2=\operatorname{Rp} 19.925 .218 .545$
c) Kondisi $3=\mathrm{Rp} \quad 3.744 .000 .000$
d) Kondisi $4=\operatorname{Rp} \quad 4.992 .000 .000$

\section{B. Saran}

Saran yang dapat diberikan berdasarkan hasil analisa dalam Tugas Akhir ini adalah sebagai berikut :

1) Adanya uji laboratorium untuk mendapatkan parameter fisis tanah lainnya, sehingga perencaan akan lebih akurat.

2) Sebaiknya analisa zona likuifaksi dilakukan terhadap aspek gradasi dan juga aspek tegangan. Sehingga analisa terhadap lapisan tanah yang berpotensi likuifaksi lebih akurat. Oleh karena itu perlu dilakukan analisa ayakan untuk mendapatkan kurva gradasi butiran tanah.

3) Perhitungan biaya perencanaan pondasi dilakukan lebih detail lagi. Karena harga tiang pancang dapat dipengaruhi oleh banyak hal, seperti: diameter tiang, panjang per segmen tiang, dan lokasi proyek.

\section{DAFTAR PUSTAKA}

[1] Jurusan Teknik Sipil FTSP-ITS. 2002. Modul H : Perencanaan Tiang Pancang. Surabaya : Jurusan Teknik Sipil FTSP - ITS.

[2] Wahyudi, Herman. 2013. Daya Dukung Pondasi Dalam. Surabaya : Jurusan Teknik Sipil FTSP - ITS.

[3] Madabhushi, G., Jonathan K., dan Stuart H. 2010. Design of Pile Foundation in Liquefiable Soils. London : Imperial College Press.

[4] Das, Braja M. 1985. Mekanika Tanah (Prinsip-prinsip Rekayasa Geoteknis. Diterjemahkan oleh Indrasurya B.M. dan Noor E.M. Jakarta : Penerbit Erlangga.

[5] Bhattacharya, S. 2003. "A Reconsideration of the Safety of Piled Bridge Foundations in Liquefiable Soils". Proceeding Soils and Foundations Japanese Geotechnical Society. Vol. 45, No.4, 13.25, Aug. 2005.

[6] Idriss, I.M., and R.W. Boulanger. 2010. SPT-Based Liquefaction Triggering Procedures. California : Center For Geotechnical Modeling University of California. 